\title{
Clinical diagnosis of heart failure in nursing home residents based on history, physical exam, BNP and ECG
}

Citation for published version (APA):

Daamen, M. A. M. J., Brunner-la Rocca, H. -P., Tan, F. E. S., Hamers, J. P. H., \& Schols, J. M. G. A. (2017). Clinical diagnosis of heart failure in nursing home residents based on history, physical exam, BNP and ECG: Is it reliable? European Geriatric Medicine, 8(1), 59-65.

https://doi.org/10.1016/j.eurger.2016.10.003

Document status and date:

Published: 01/02/2017

DOI:

10.1016/j.eurger.2016.10.003

Document Version:

Publisher's PDF, also known as Version of record

\section{Document license:}

Taverne

Please check the document version of this publication:

- A submitted manuscript is the version of the article upon submission and before peer-review. There can be important differences between the submitted version and the official published version of record.

People interested in the research are advised to contact the author for the final version of the publication, or visit the DOI to the publisher's website.

- The final author version and the galley proof are versions of the publication after peer review.

- The final published version features the final layout of the paper including the volume, issue and page numbers.

Link to publication

\footnotetext{
General rights rights.

- You may freely distribute the URL identifying the publication in the public portal. please follow below link for the End User Agreement:

www.umlib.nl/taverne-license

Take down policy

If you believe that this document breaches copyright please contact us at:

repository@maastrichtuniversity.nl

providing details and we will investigate your claim.
}

Copyright and moral rights for the publications made accessible in the public portal are retained by the authors and/or other copyright owners and it is a condition of accessing publications that users recognise and abide by the legal requirements associated with these

- Users may download and print one copy of any publication from the public portal for the purpose of private study or research.

- You may not further distribute the material or use it for any profit-making activity or commercial gain

If the publication is distributed under the terms of Article $25 \mathrm{fa}$ of the Dutch Copyright Act, indicated by the "Taverne" license above, 


\title{
Clinical diagnosis of heart failure in nursing home residents based on history, physical exam, BNP and ECG: Is it reliable?
}

\author{
M.A.M.J. Daamen ${ }^{\text {a, }}{ }^{,}$, H.-P. Brunner-la Rocca ${ }^{\text {b }}$, F.E.S. Tan ${ }^{\text {c }}$, J.P.H. Hamers ${ }^{a}$, J.M.G.A. Schols ${ }^{a, d}$ \\ ${ }^{a}$ Department of Health Services Research, Research School Caphri, Maastricht University, PO Box 616, 6200MD Maastricht, The Netherlands \\ b Department of Cardiology, Maastricht University Medical Centre, PO Box 5800, 6202AZ Maastricht, The Netherlands \\ ${ }^{\mathrm{c}}$ Department of Methodology and Statistics, Research School Caphri, Maastricht University, PO Box 616, 6200MD Maastricht, The Netherlands \\ ${ }^{\mathrm{d}}$ Department of Family Medicine, Research School Caphri, Maastricht University, Maastricht, PO Box 616, 6200MD The Netherlands
}

\section{A R T I C L E I N F O}

\section{Article history:}

Received 18 June 2016

Accepted 12 October 2016

Available online 9 November 2016

\section{Keywords:}

Heart failure

Diagnosis

Nursing home

Diagnostic accuracy

Echocardiography

\begin{abstract}
A B S T R A C T
Introduction: Heart failure (HF) is highly prevalent in nursing home residents. To diagnose HF properly, echocardiography is recommended by cardiology guidelines. In nursing homes, the nursing home physician (NHP) usually diagnoses HF based on history, clinical examination, electrocardiography (ECG) and levels of B-type natriuretic peptide only, which is in contrast to the cardiologist who probably always will apply for an echocardiogram. Therefore, we aimed (1) to investigate the agreement on the diagnosis of HF made by the NHP without echocardiography and (2) to determine the clinical characteristics that may contribute to the proper diagnosis of HF in nursing home residents.

Materials and methods: The study followed a cross-sectional design. Nursing home residents in the southern part of the Netherlands, aged over 65 years and receiving long-term somatic or psychogeriatric care, were included in the study. The NHP decided (stepwise) on the diagnosis of HF; first after anamnesis and physical examination, second after additional information on NTproBNP and ECG, and finally, on all available information, except echocardiography. An expert team consisting of two cardiologists and one hospital geriatrician decided on the final diagnosis, based on all available information.

Results and conclusion: There was an overall agreement on both correctly identifying residents with $\mathrm{HF}$ and correctly excluding HF of $80.4 \%$ (kappa 0.57 ). Characteristics with a high contribution in predicting HF were a history of HF, a high NT-proBNP level, the presence of rales, arrhythmias and use of cardiac medication. NHPs are fairly capable of diagnosing HF in nursing home residents without echocardiography.
\end{abstract}

(c) 2016 Elsevier Masson SAS and European Union Geriatric Medicine Society. All rights reserved.

\section{Introduction}

Heart failure (HF) is a common chronic disease. Its prevalence increases with age and it is very frequent among nursing home residents [1,2]. Nursing home residents are a specific group of very frail and considerably disabled patients, with high levels of care dependency due to chronic somatic diseases or progressive dementia. The care they need is beyond the range of regular home care services [3].

\footnotetext{
* Corresponding author. Tel.: +31 613778368.

E-mail addresses: m.vandervelden@maastrichtuniversity.nl (M.A.M.J. Daamen), hp.brunnerlarocca@mumc.nl (H.-P. Brunner-la Rocca),

frans.tan@maastrichtuniversity.nl (F.E.S. Tan),jph.hamers@maastrichtuniversity.nl (J.P.H. Hamers), jos.schols@maastrichtuniversity.nl (J.M.G.A. Schols).
}

Typical signs and symptoms of HF, such as dyspnoea and oedema, and a structural or functional cardiac impairment as assessed by cardiac imaging indicate the presence of HF [4]. In order to diagnose HF, a structured diagnostic workup including medical history, physical examination, electrocardiography (ECG), assessment of cardiac markers (natriuretic peptides) and echocardiography is recommended for proper diagnosis [4]. However with increasing age, diagnosis of HF becomes more complex, often complicated by geriatric syndromes including frailty, symptoms of co-morbidities and psychogeriatric disorders, which may lead to misinterpretation [5-7]. Therefore, the diagnosis may be uncertain if solely based on signs and symptoms without echocardiography to seek underlying cardiac dysfunction.

Moreover, the distinction between HF with reduced, mid-range and preserved left-ventricular ejection fraction as well as the detection of potentially correctable underlying causes of HF such 
as aortic stenosis may have important therapeutic consequences $[4,8,9]$. A false positive diagnosis of HF may lead to unnecessary treatment in a population that is already at high risk for adverse drug reactions and often receiving multiple other drugs, whereas unrecognised $\mathrm{HF}$ is associated with impaired quality of life and hospitalisation. Since early diagnosis and treatment of HF may prevent progression and lead to improvement of quality of life, it is essential that HF is diagnosed adequately particularly in this population [10]. However, due to functional limitations or resistance against hospital referrals and unavailability of on-site echocardiography, it is difficult to perform echocardiography in nursing home residents suspected to have HF. Consequently, the physician attending nursing homes usually diagnose HF without involvement of a cardiologist. In most Western countries, physicians attending nursing homes are general practitioners providing medical care to the residents. In the Netherlands, physicians have completed a specialist training programme to become a qualified nursing home physician (NHP) [11]. NHPs may diagnose HF based on clinical signs and symptoms only, possibly supported by ECG and levels of B-type natriuretic peptides (BNP or $\mathrm{N}$-terminal pro BNP [NT-proBNP]).

To the best of our knowledge, there are no studies in which the diagnostic accuracy for HF, diagnosed using the available tools without echocardiography, assessed by NHPs is described. Studies in primary health care with general practitioners having the same limited diagnostic tools, showed that the diagnosis of HF was confirmed by echocardiography only in about $30 \%$ of cases $[12,13]$. Two recent studies in nursing home residents have reported that a previous diagnosis of HF could not be confirmed in $78 \%$ and $62 \%$ of cases, respectively. However, in these studies it was not known who made the diagnosis of HF before and which diagnostic tools were used $[2,14]$.

This study investigated the accuracy of diagnosing HF by NHPs, based on clinical assessment (history, physical examination), diagnostic tests generally available in nursing homes (i.e. ECG and NT-proBNP), and additional information such as comorbidities, medication and additional blood testing, as compared to an expert team additionally using echocardiography (gold standard). Moreover, we determined the clinical characteristics which may contribute to a correct diagnosis of HF in those residents where there was doubt about the presence or absence of HF by the NHP.

\section{Materials and methods}

This study followed a multi-centre cross-sectional design as previously published [15]. The study protocol complied with the declaration of Helsinki and has been granted approval from the Medical Ethics Committee of Maastricht University/Academic Hospital Maastricht (NL33281.068.10/MEC10-3-074). The study has been registered in the Netherlands National Trial Register (NTR2663).

\subsection{Study design and sample}

This study was carried out between January 2011 and June 2013 in five long-term care organisations in the southern parts of the Netherlands, with an overall number of about 4500 nursing home residents. Within the specified time period, it was feasible to ask unselected nursing home residents at 28 locations $(n=1920)$ allocated to these five long-term care organisations (3-8 per organisation) to participate in the study. These residents received chronic somatic care or psychogeriatric care and were over 65 years of age. Residents who received palliative care or were admitted for short-term rehabilitation (staying $<2$ months) were excluded. Informed written consent was obtained from the residents themselves or from their legal representatives in the case of psychogeriatric residents or residents with aphasia.

\subsection{Study procedure of the heart failure assessment}

Before the start of the inclusion of participants, all participating NHPs (3-4 per organisation) had received a refresher course regarding diagnosing $\mathrm{HF}$ and performing a structured physical examination by HF experts of the department of Cardiology at Maastricht University Medical Centre. The refresher course included a review of signs and symptoms of HF followed by bedside teaching ( $3 \mathrm{~h}$ ), a lecture on ECG findings in relation to HF ( 2 hours) and a visit to the outpatient HF clinic of the Maastricht University Medical Centre ( $3 \mathrm{~h}$ ). NHPs took the cardiac history, anamnesis and performed the physical examination. They were blinded to pre-existing information about the residents with the exception of their name and date of birth. The medical history and physical examination were recorded in a case record file (CRF) developed for this study. In residents having somatic disorders only the history-related questions were answered by the residents themselves; in psychogeriatric residents, these questions were answered by the nurses responsible for their daily care and/or the main family caregiver of the resident.

Two research nurses and a NHP/researcher were responsible for recording the ECG, collecting a blood sample, gathering data from the medical records and filling in the questionnaires. Qualified (fellow) cardiologists recorded the echocardiogram on-site using a mobile echocardiography device (Philips CX50, Eindhoven NL).

To determine NT-proBNP levels, venous blood samples were analysed at the clinical chemistry laboratory at Maastricht University Medical Centre on an Elecsys 2010 (Roche Diagnostics, Mannheim, Germany). A standard 12-lead ECG was made using Cardiovit AT-10 plus (Schiller, Switzerland).

Standard echocardiography from parasternal, apical and subcostal view was performed and analyses were done according to the recommendation of the American Society of Echocardiography [16].

\subsection{Diagnosis of heart failure by nursing home physician}

The NHP was asked to decide on the diagnosis of HF at three different stages. First, after medical history (including cardiac history) and physical examination, by answering absent, present, probably or possible. Second after the additional information on NT-proBNP and ECG, the NHP decided again, using the same four answer options. Finally, the NHP received additional information about medication, comorbidities and additional blood analysis and had to decide whether HF was present or absent.

\subsection{Diagnosis of heart failure by expert team}

An expert team of two cardiologists and a geriatrician was responsible for the final diagnosis of $\mathrm{HF}$ based on all the data collected as mentioned above, according to the current guidelines of the European Society of cardiology (ESC) [17].

The members of the expert team judged all files independently. When there was mutual agreement on the diagnosis, the file was closed. All files with some disagreement were discussed in the presence of all three members of the expert team to ultimately reach consensus and make a final diagnosis.

\subsection{Statistical analysis}

Statistical analyses were performed using IBM SPSS statistics software version 22. Descriptive frequency distributions for all variables were determined. Differences between groups were tested using Student's $T$ tests or Mann-Whitney $U$-test (parametric and 
non-parametric testing) and Chi-square test (cross-table analysis). $P$-values of $<0.05$ were considered statistically significant.

The accuracy of the diagnosis of HF by the NHP versus the expert team was determined by the number of true and false positive diagnoses. The results are presented by sensitivity, specificity and positive and negative predictive values. To predict the presence or absence of HF in the group of residents where there was uncertainty about the diagnosis by the NHP (HF probably or possible), a statistical model was created using the statistical significant characteristics $(P$-value $<0.05)$ of the demographic and clinical characteristics based on the diagnosis of HF by the expert team. In order to reduce the number of variables included in the multivariable model, some characteristics were combined and recoded to a new variable. Dyspnoea is a combination of New York Heart Association classification, orthopnoea and paroxysmal nocturnal dyspnoea. Coronary artery disease included myocardial infarction, coronary bypass graft and coronary ischaemia. Cardiac medication included the use of a diuretic, a beta-blocker or an angiotensin converting enzyme inhibitor. Arrhythmia was recoded in case of an irregular heartbeat, arrhythmia in the history, atrial fibrillation on the ECG and presence of a pacemaker. Multivariable logistic regression analysis was performed and variables with a $P$ value $>0.05$ were subsequently excluded using the backward procedure. Multi-collinearity was tested with collinearity diagnostics; tolerance, VIF, eigenvalues and variance proportions. The probability values in each subject of the regression analysis were used as a test value for diagnostic accuracy in a ROC curve analysis. The cut-off point with the highest sum of sensitivity and specificity was used to determine the predictive value of the model [18]. The percentage of missing values for the logistic regression was $7.7 \%$. To prevent biased results, missing values were imputed prior to logistic regression using the multiple imputation procedure.

\section{Results}

\subsection{Study sample}

After applying the exclusion criteria, 27\% $(n=513)$ of the approached residents or their legal representatives, agreed to participate in the study as depicted in Fig. 1. Although there is no

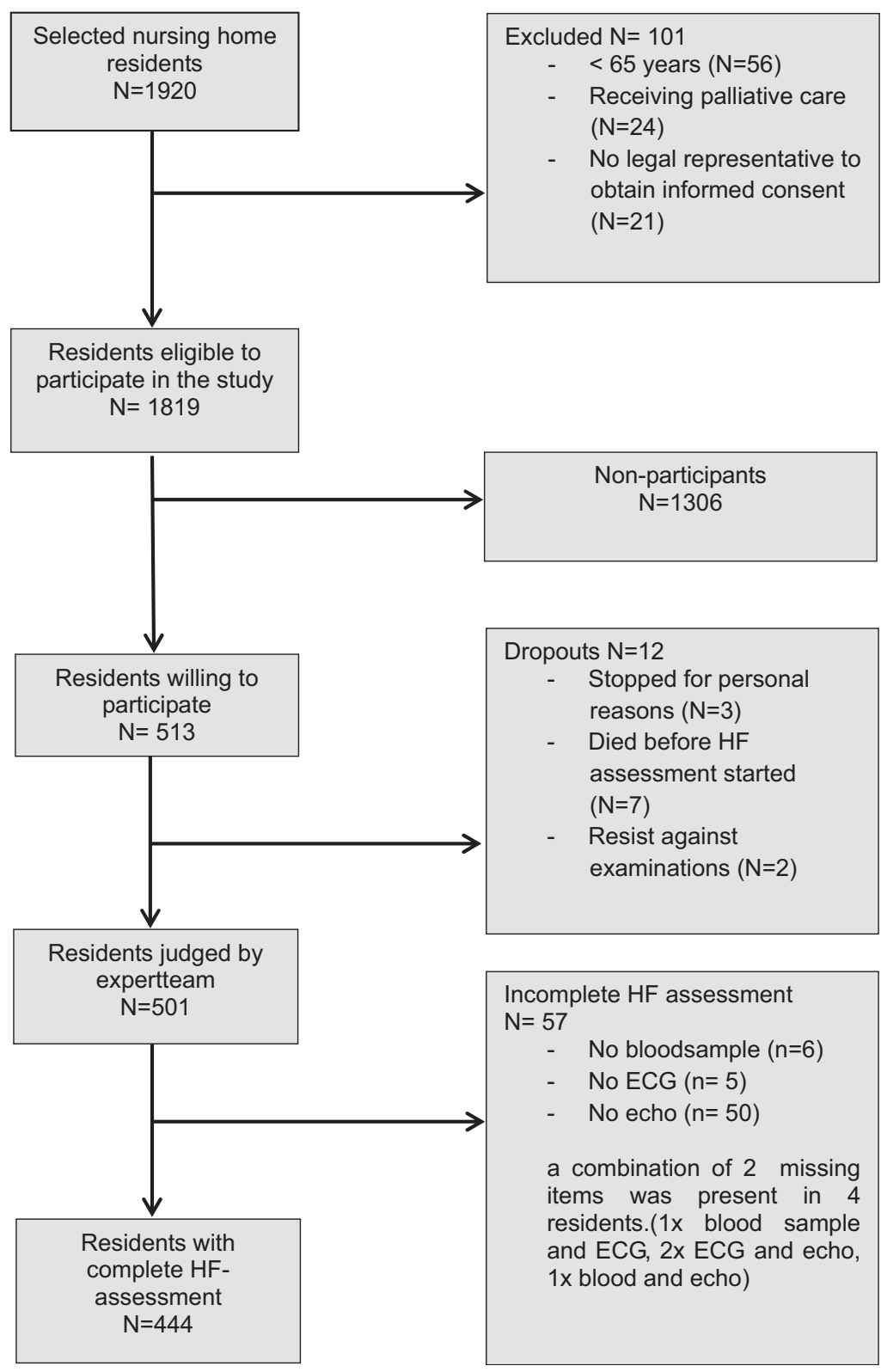

Fig. 1. Flowchart of residents participation. 
Table 1

Demographic and clinical characteristics of nursing home residents diagnosed with and without heart failure by the expert team.

\begin{tabular}{|c|c|c|c|}
\hline \multirow[t]{2}{*}{ Variables } & \multicolumn{3}{|c|}{$\begin{array}{l}\text { Residents with and without HF diagnosed by the } \\
\text { expert team }\end{array}$} \\
\hline & $\begin{array}{l}\text { No HF, } \\
n=299\end{array}$ & $\begin{array}{l}\text { HF present, } \\
n=145\end{array}$ & $P$-value \\
\hline Age (years) mean (SD) & $81(7)$ & $84(6)$ & $<.001$ \\
\hline Gender, male & $105(35)$ & 57 (39) & 0.389 \\
\hline Psychogeriatric & $199(67)$ & 85 (59) & 0.102 \\
\hline \multicolumn{4}{|l|}{ Symptoms \% } \\
\hline NYHA 1 & $210(70)$ & $60(42)$ & $<.001$ \\
\hline NYHA 2 & $49(16)$ & $45(32)$ & \\
\hline NYHA 3 & $25(8)$ & $28(20)$ & \\
\hline NYHA 4 & $13(4)$ & $10(7)$ & \\
\hline Orthopnea & $26(9)$ & $29(20)$ & 0.003 \\
\hline Palpitation & $23(8)$ & $37(26)$ & $<.001$ \\
\hline PND & $17(6)$ & $17(12)$ & 0.041 \\
\hline Fatigue & $96(32)$ & $61(42)$ & 0.096 \\
\hline \multicolumn{4}{|l|}{ Physical examination } \\
\hline $\begin{array}{l}\text { Heart rate }(\mathrm{bpm}) \\
\text { mean }(\mathrm{SD})\end{array}$ & $72(12)$ & $74(16)$ & 0.253 \\
\hline $\begin{array}{l}\text { Systolic BP (mmHg) } \\
\text { mean }(\mathrm{SD})\end{array}$ & $140(25)$ & $136(26)$ & 0.117 \\
\hline $\begin{array}{l}\text { Diastolic BP (mmHg) } \\
\text { mean }(\mathrm{SD})\end{array}$ & $75(13)$ & $74(15)$ & 0.179 \\
\hline Increased JV pressure & $63(21)$ & $52(36)$ & 0.002 \\
\hline Hepatomegaly & $16(5)$ & $13(9)$ & 0.229 \\
\hline Oedema & $149(50)$ & $96(66)$ & 0.001 \\
\hline Murmurs & $98(33)$ & $65(45)$ & 0.015 \\
\hline Irregular heart beat & $41(14)$ & $63(43)$ & $<.001$ \\
\hline Rales & $68(23)$ & $67(46)$ & $<.001$ \\
\hline Pleural effusion & $14(5)$ & $18(12)$ & 0.005 \\
\hline \multicolumn{4}{|l|}{ Cardial history } \\
\hline Myocardial infarction & $31(10)$ & $36(25)$ & $<.001$ \\
\hline Arrhythmia & $33(11)$ & 57 (39) & $<.001$ \\
\hline Coronary ischaemia & $49(16)$ & $46(32)$ & 0.001 \\
\hline Valvular heart disease & $11(4)$ & $21(15)$ & $<.001$ \\
\hline Coronary bypass graft & $16(5)$ & $22(15)$ & 0.001 \\
\hline Pace maker & $8(3)$ & $11(8)$ & 0.035 \\
\hline Heart failure in history & $32(11)$ & $68(47)$ & $<.001$ \\
\hline \multicolumn{4}{|l|}{ Co-morbidity } \\
\hline Diabetes mellitus & $57(19)$ & $35(24)$ & 0.216 \\
\hline COPD & $42(14)$ & $31(21)$ & 0.051 \\
\hline CVA & $113(38)$ & $64(44)$ & 0.200 \\
\hline \multicolumn{4}{|l|}{ Cardiac risk factors } \\
\hline Hypertension & $126(42)$ & $78(54)$ & 0.021 \\
\hline Hypercholesterolemia & $79(26)$ & $35(24)$ & 0.65 \\
\hline Smoking & $42(14)$ & $17(12)$ & 0.113 \\
\hline \multicolumn{4}{|l|}{ Cardiac medication } \\
\hline Diuretics & $88(29)$ & $87(60)$ & $<.001$ \\
\hline Beta-blocker & $65(22)$ & $72(50)$ & $<.001$ \\
\hline ACE-inhibitor & $44(15)$ & $38(26)$ & 0.003 \\
\hline ARB-antagonist & $30(10)$ & $15(10)$ & 0.919 \\
\hline \multicolumn{4}{|l|}{ Blood sample } \\
\hline $\begin{array}{l}\text { NT-pro BNP pg/ml } \\
\text { median (IQR) }\end{array}$ & $245(330)$ & $1133(1505)$ & $<.001$ \\
\hline $\begin{array}{l}\text { Haemoglobin } \\
\text { mmol/l mean (SD }\end{array}$ & $8.1(0.9)$ & $7.8(0.9)$ & 0.002 \\
\hline $\begin{array}{l}\text { Creatinine } \mu \mathrm{mol} / \mathrm{l} \\
\text { mean }(\mathrm{SD})\end{array}$ & $82(45)$ & $100(64)$ & 0.001 \\
\hline \multicolumn{4}{|l|}{ Additional } \\
\hline BMI $\left(\mathrm{kg} / \mathrm{m}^{2}\right)$ mean $(\mathrm{SD})$ & $25(5)$ & $26(5)$ & 0.090 \\
\hline \multicolumn{4}{|l|}{ Electrocardiography } \\
\hline Abnormal & $217(73)$ & $132(91)$ & $<.001$ \\
\hline $\begin{array}{l}\text { Left ventricular } \\
\text { hypertrophy }\end{array}$ & $15(5)$ & $12(8)$ & 0.178 \\
\hline Pathological Q-wave & 87 (29) & $55(38)$ & 0.061 \\
\hline Atrial fibrillation & $25(8)$ & $49(34)$ & $<.001$ \\
\hline Left bundle branch block & $11(4)$ & $18(12)$ & $<.001$ \\
\hline Sinustachycardia & $8(3)$ & $8(6)$ & 0.132 \\
\hline Sinusbradycardia & $37(12)$ & $9(6)$ & 0.046 \\
\hline
\end{tabular}

\begin{tabular}{|c|c|c|c|}
\hline \multirow[t]{2}{*}{ Variables } & \multicolumn{3}{|c|}{$\begin{array}{l}\text { Residents with and without HF diagnosed by the } \\
\text { expert team }\end{array}$} \\
\hline & $\begin{array}{l}\text { No HF, } \\
n=299\end{array}$ & $\begin{array}{l}\text { HF present, } \\
n=145\end{array}$ & $P$-value \\
\hline \multicolumn{4}{|l|}{ Echocardiography } \\
\hline LVEDD $n=309$ mean (SD) & $43(8)$ & $45(9)$ & 0.116 \\
\hline LVESD $n=284$ mean (SD) & $29(6)$ & $34(10)$ & $<.001$ \\
\hline LVEF $n=399$ mean $(S D)$ & $59(9)$ & $49(14)$ & $<.001$ \\
\hline $\mathrm{EF} \geq 50 \%, n=309$ & $239(89)$ & $70(52)$ & \\
\hline $\mathrm{EF} 40-49 \%, n=54$ & $7(8)$ & $34(26)$ & \\
\hline $\mathrm{EF} \leq 39 \%, n=36$ & $7(3)$ & $29(22)$ & \\
\hline E/A ratio mean (range) & $0.74(0.27-3.25)$ & $1.22(0.31-4.45)$ & $<.001$ \\
\hline E/E' ratio mean (range) & $10.7(3.45-27.8)$ & $15.2(3.8-36.7)$ & $<.001$ \\
\hline $\begin{array}{l}\text { Left atrial volume } \\
\qquad n=254 \text { mean }(S D)\end{array}$ & $54(20)$ & $80(38)$ & $<.001$ \\
\hline \multicolumn{4}{|l|}{ Valvular function ${ }^{\mathrm{a}}$} \\
\hline Aortic stenosis & $15(5)$ & $20(14)$ & 0.001 \\
\hline Aortic regurgitation & $18(6)$ & $18(12)$ & 0.019 \\
\hline Mitralic regurgitation & $17(6)$ & $26(18)$ & $<.001$ \\
\hline
\end{tabular}

Numbers indicate number of patients (\%) unless otherwise indicated.

NYHA, New York Hear Association; bpm, beats per minute; BP, blood pressure; PND, paroxysmal nocturnal dyspnoea; JV, jugular vein; COPD, chronic obstructive pulmonary disease; CVA, Cerebro-vascular accident; BMI, body mass index; ACE, angiotensine converting enzyme; ARB, angiotensin receptor blocker; LVEDD, left ventricular end diastolic diameter; LVESD, left ventricular end systolic diameter; LVEF, left ventricular ejection fraction; $\mathrm{EF}$, ejection fraction; E/A, ratio of early to late diastolic mitral inflow waves $\mathrm{E} / \mathrm{e}^{\prime}$ ratio of the mitral inflow $\mathrm{E}$ wave to the tissue Doppler e' wave.

a Moderate to severe only.

information available about exact numbers, the main reasons for not participating were that residents considered themselves too old or believed that the investigations were too burdensome. Compared to participants, in the non-participating residents group, there were more women (71\% versus $64 \%$ ) in which a few with very high age, resulting in a slightly higher mean age in this group (83 versus 82 ).

There were $n=444$ residents with a complete HF assessment (history, physical examination, ECG and echocardiography).

\subsection{Demographic and clinical characteristics}

An overview of demographic and clinical characteristics of the 444 residents with complete data is presented in Table 1. Residents with HF showed significantly more typical signs and symptoms of HF such as increased vena jugularis pressure and rales. Hypertension and oedema were highly prevalent in residents with and without HF. NT-proBNP was higher and reduced or mid-range LVEF was more common in HF patients.

\subsection{Diagnosis of heart failure by nursing home physician and expert team}

The expert team diagnosed HF in 145 of the 444 nursing home residents (33\%). The decisions on HF by the NHPs at the three different stages in the HF- assessment are shown in Table 2. After anamnesis and physical examination, HF was diagnosed by the NHPs in only a minority of patients and no definite decision could be made in more than half. After the additional information about ECG and NT-proBNP, the uncertainty (HF possible or probably) only slightly diminished (from $51 \%$ to $48 \%$ ). Finally, after deciding on all the available information the NHP diagnosed more HF than the expert team. Concordance with the presence or absence of HF was reached in $80.4 \%$ of cases

\subsection{Predictors of heart failure}

To determine variables contributing to the diagnosis of HF the characteristics included in the multivariable logistic regression 
Table 2

Diagnosis of HF by Nursing Home Physician (NHP) at three different stages comparison to expert team.

\begin{tabular}{llrcc}
\hline & NHP $(n)$ & & \multicolumn{2}{c}{ Expert team $(n)^{\mathrm{a}}$} \\
\cline { 3 - 5 } & & & HF present & HF absent \\
\hline Stage 1 & HF present & 13 & 9 & 4 \\
& HF absent & 204 & 32 & 172 \\
& HF probably present & 40 & 27 & 13 \\
& HF possible present & 187 & 77 & 110 \\
Stage 2 & HF present & 20 & 19 & 1 \\
& HF absent & 213 & 17 & 196 \\
& HF probably present & 51 & 39 & 12 \\
& HF possible present & 160 & 70 & 90 \\
Stage 3 & HF present & 160 & 109 & 51 \\
& HF absent & 284 & 36 & 248 \\
\hline
\end{tabular}

Decision on the diagnosis of HF by the NHP at three different stages: Stage 1: After cardiac history, anamnesis and physical examination. Stage 2: After additional information on ECG and NT-pro BNP measurement. Stage 3: After anamnesis, physical examination, ECG, NT-pro BNP measurement and additional information about co-morbidity and medication.

a The expert team diagnosed HF on the information at stage 3 and the echocardiography

were: age, increased jugular venous pressure, oedema, rales, dyspnoea, history of HF, CAD, valvular heart disease, arrhythmia, abnormal ECG, NT-proBNP value, haemoglobin, creatinine and cardiac medication. Odds ratios of variables that significantly differed between residents with and without $\mathrm{HF}$ in the univariate model are depicted in Table 3. The final model (Table 3) showed that characteristics with a high contribution in independently predicting HF were a history of HF, NT-proBNP levels, presence of rales, arrhythmia, dyspnoea, increased jugular vein pressure and using cardiac medication.

\subsection{Accuracy of diagnosis of heart failure}

At stage 1 and 2 the NHP did not make a definite decision in 227 and 211 residents, respectively (HF probably or possible in Table 2). In order to determine the presence or absence of HF in these groups, the variables of the final model (Table 3 ) were used as predictors for the presence of HF. The probability value was used as a test variable in the ROC-curve analysis. Using the ROC-curve analysis, it appeared that a cut-off point of a probability of HF of 0.24 is the optimal choice in the sense that the sum of sensitivity and specificity was largest (using Youden criterion index) [18]. Consequently, if the probability of HF was larger than 0.24 , the patient was classified as having HF. The accuracy of diagnosing HF by the NHP in combination with these predictors in case of uncertainty as compared to the expert team opinion for stage 1 and 2 is presented in Table 4. In case this model is used, the test characteristics (sensitivity, specificity, positive and negative predictive value) showed a slightly more favourable outcome as compared to the forced decision whether HF is present or not at the final stage (Table 4). For example, using the model in stage 2 for the group of residents classified as probably or possible HF leads to a sensitivity of $83 \%$ versus $75 \%$ at stage 3 (forced decision), a specificity of $85 \%$ versus $83 \%$ at stage 3 and an overall agreement of $84 \%$ (kappa 0.65 ) versus $80 \%$ (kappa 0.57 ). The performed tests for multi-collinearity showed no collinearity. Results after imputation of missing values were compared to the results of the original data and showed no significant changes.

\section{Discussion}

This study in unselected nursing-home residents shows a concordance with the presence or absence of $\mathrm{HF}$ in $80 \%$ of patients as decided by the NHP with the available tools in the nursing home compared to an expert team of cardiologists and a geriatrician that also had the results of the echocardiography. In addition, there was a high contribution in independently predicting HF based on history of HF, NT-proBNP levels, presence of rales, arrhythmia and using cardiac medication.

Diagnosis of HF by NHPs based on anamnesis, physical examination, ECG and NT-proBNP values results more often in over- than under-diagnosis of HF. Nursing home residents may benefit from accurately diagnosed HF by the NHP, which saves them a burdensome visit to a cardiologist due to functional and cognitive limitations. On the other hand, unnecessary treatment as a result of false positive diagnosis is also not preferable because of the high risk of adverse drugs reaction [19]. Therefore, the question arises as to whether a $70 \%$ correct diagnosis of $\mathrm{HF}$ (positive predictive value) is acceptable for nursing home residents. Unfortunately, to the best of our knowledge, there are no other studies on the diagnostic accuracy by NHPs or physicians attending nursing homes. Available studies in primary care show a correct diagnosis of HF between 26 and 50\% only [12,13]. Thus, a finding of almost $70 \%$ agreement in our study may be considered a positive result. However, this still means that almost one in three would not receive the correct treatment.

Hence, it is questionable whether it is possible to reduce the number of residents with a false positive or false negative

Table 3

Possible predictors for the presence of heart failure (HF) in nursing home residents.

\begin{tabular}{|c|c|c|c|c|c|c|}
\hline \multirow[t]{2}{*}{ Variable } & \multicolumn{3}{|c|}{ Univariate model } & \multicolumn{3}{|c|}{ Final model } \\
\hline & OR & $95 \%-\mathrm{CI}$ & $P$-value & OR & $95 \%-\mathrm{CI}$ & $P$-value \\
\hline Age & 0.98 & $0.93-1.03$ & 0.37 & & & \\
\hline Rales & 2.38 & $\begin{array}{l}1.15-4.95 \\
1.07\end{array}$ & 0.02 & 2.32 & $1.15-4.65$ & 0.02 \\
\hline Increased JVP & 1.92 & $0.97-3.77$ & 0.06 & 2.01 & $1.05-3.84$ & 0.03 \\
\hline Dyspnoea & 0.46 & $0.23-0.92$ & 0.03 & 0.48 & $0.24-0.96$ & 0.04 \\
\hline Oedema & 1.47 & $\begin{array}{l}0.79-2.75 \\
3.05\end{array}$ & 0.23 & & & \\
\hline Arrhythmia & 2.23 & $1.14-4.35$ & 0.02 & 2.32 & $1.21-4.43$ & 0.01 \\
\hline CAD & 1.02 & $0.53-1.96$ & 0.95 & & & \\
\hline Valvular heart disease & 0.94 & $0.69-1.30$ & 0.72 & & & \\
\hline HF in history & 6.48 & $3.20-13.14$ & $<.001$ & 6.48 & $3.24-12.94$ & $<.001$ \\
\hline ECG & 1.67 & $0.67-4.14$ & 0.27 & & & \\
\hline Ln NT-proBNP & 5.06 & $3.36-7.62$ & $<.001$ & 4.87 & $3.34-7.10$ & $<.001$ \\
\hline Cardiac medication & 2.58 & $1.33-5.02$ & 0.01 & 2.61 & $1.39-4.91$ & 0.003 \\
\hline Haemoglobulin & 0.91 & $0.65-1.28$ & 0.60 & & & \\
\hline Creatinine & 1.00 & $0.99-1.00$ & 0.22 & & & \\
\hline
\end{tabular}

JVP, jugular vein pressure; CAD, coronary artery disease; HF, heart failure; ECG, electrocardiography. 
Table 4

Agreement of the diagnosis of HF by the nursing home physician versus expert team using a model.

\begin{tabular}{|c|c|c|c|c|c|c|c|}
\hline \multicolumn{2}{|l|}{ Stages } & \multicolumn{6}{|c|}{ Cross-table } \\
\hline \multirow[t]{5}{*}{ Stage 1} & \multirow[t]{5}{*}{ NHP versus expert team ${ }^{a}$} & \multirow[t]{2}{*}{ NHP } & \multicolumn{3}{|l|}{ Expert team } & Sensitivity $74 \%$ & $95 \% \mathrm{Cl}$ \\
\hline & & & $\mathrm{HF}^{+}$ & $\mathrm{HF}-$ & & Specificity $86 \%$ & $66-81$ \\
\hline & & $\mathrm{HF}+$ & 107 & 43 & 150 & PPV 71\% & $82-90$ \\
\hline & & $\mathrm{HF}_{-}$ & 38 & 256 & 294 & NPV 87\% & $63-78$ \\
\hline & & & 145 & 299 & 444 & & $83-91$ \\
\hline \multirow[t]{5}{*}{ Stage 2} & \multirow[t]{5}{*}{ NHP versus expert team ${ }^{\mathrm{a}}$} & NHP & \multirow{2}{*}{\multicolumn{3}{|c|}{$\begin{array}{l}\text { Expert team } \\
\text { HF+ }\end{array}$}} & Sensitivity $83 \%$ & \\
\hline & & & & & & Specificity $85 \%$ & $76-89$ \\
\hline & & $\mathrm{HF}+$ & 121 & 46 & 167 & PPV 72\% & $81-89$ \\
\hline & & $\mathrm{HF}-$ & 24 & 253 & 277 & NPV 91\% & $65-79$ \\
\hline & & Total & 145 & 299 & 444 & & $87-94$ \\
\hline \multirow[t]{5}{*}{ Stage 3} & \multirow[t]{5}{*}{ NHP versus expert team } & NHP & \multicolumn{3}{|l|}{ Expert team } & Sensitivity $75 \%$ & \\
\hline & & & $\mathrm{HF}+$ & $\mathrm{HF}-$ & & Specificity $83 \%$ & $67-82$ \\
\hline & & $\mathrm{HF}+$ & 109 & 51 & 160 & PPV 68\% & $78-87$ \\
\hline & & $\mathrm{HF}-$ & 36 & 248 & 284 & NPV $87 \%$ & $60-75$ \\
\hline & & Total & 145 & 299 & 444 & & $83-91$ \\
\hline
\end{tabular}

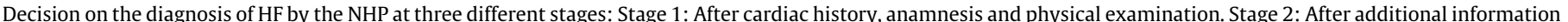

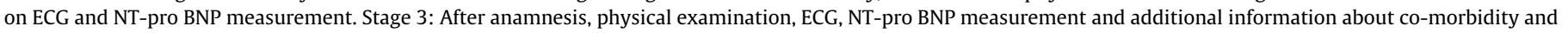
medication.

PPV, positive predictive value, NPV, negative predictive value.

a Using the final model (Table 3 ) for the group probably/possible HF (Table 2).

diagnosis of HF made by an NHP. With the logistic regression model created to predict HF based on clinical characteristics, we could reduce the number of false positives to nearly one in four by employing the model when there is doubt about the diagnosis (HF probably or possible). The false negative diagnosis decreased from 13 to $9 \%$.

In the past, several scores in different patient groups to predict HF were developed. Mosterd et al. (1997) reviewed six HF scores for the detection of possible and definite HF and found a high sensitivity for the detection of definite HF, but a lower sensitivity for the detection of possible HF [20]. Unfortunately, most of these scores are not applicable for nursing homes residents because they require a chest $\mathrm{X}$-ray and the patients included usually differed significantly from our population. However, none of these scores used the cardiac marker NT-proBNP to predict the presence of HF. A recent study by Oudejans et al. (2011) showed an improvement in the reliability to identify the presence or absence of HF when NTproBNP levels were used [21]. They also found that loss of appetite, lower BMI and absence of wheezing were signs predicting the presence of HF. In our study, we could not confirm this, which may be related to the different population studied. In addition to differences in the occurrence of signs and symptoms, some questions are hard to answer in residents with cognitive impairments such as loss of appetite. Based on our data in a population of nursing home residents, it seems that the variables HF in history, NT-proBNP value, use of cardiac medication, arrhythmia, dyspnoea, rales and increased jugular venous pressure are best suited for more accurate detection of HF.

Although our findings support that HF is a clinical diagnosis and that a trained NHP may suspect and confirm a diagnosis of HF in residents, based on clinical history, physical examination, NTproBNP value and ECG, echocardiography is recommended by the ESC-guidelines to determine underlying causes and distinguish between HF with preserved, mid-range and reduced LVEF $[4,22]$. However, several underlying causes of HF such as hypertension (with LV hypertrophy) and atrial fibrillation can be diagnosed by physical examination and the use of an ECG only, which are ready available to NHPs. Nevertheless, there remains a group of nursing home residents in which performing echocardiography may be required, not in the context of diagnosis per se, but as basis for adequate treatment. Therefore, we strongly recommend echocardiography in these very frail and disabled old people if results directly influence decision on treatment of HF. Thus, there is a clear overlap in the pharmacological treatment of HF with reduced systolic function (HFrEF) and other cardiovascular diseases such as hypertension and coronary artery disease in which ACE- inhibitors, $\beta$-blockers mineralocorticoid-receptor antagonists may be recommended as well [23-25]. Moreover, treatment of other risk factors of HF such diabetes mellitus and HFrEF may overlap to a significant extent. Importantly, the majority of nursing-home residents have multiple of these factors. Therefore in many cases, treatment might not change if diagnosis of $\mathrm{HF}$ is more accurately established and LVEF is known. Performance of echocardiography may not add clinical value in such cases.

If in doubt however, echocardiography is necessary, particularly if residents may benefit from therapeutic interventions other than pharmacological, as in the case of valvular disorders [26]. Moreover if cardiovascular co-morbidities and/or risk factors do not require treatment with ACE-inhibition (or angiotensin-II antagonist if intolerant), $\beta$-blockers and mineralocorticoid-antagonist, knowing LVEF is required to treat patients properly, but also to prevent patients from being exposed to unnecessary treatment in case of preserved LVEF. Also, it is important to notice that some medication is contraindicated in case of reduced LVEF (e.g. verapamil, diltiazem) [4]. Taken together, if treatment significantly changes when precisely knowing the diagnosis of HF and LVEF, additional diagnostics are recommended.

The limitations in this study should be mentioned. Several NHPs were involved by performing anamnesis and physical examination in this study to diagnose HF in nursing home residents. Although the participating NHPs took a refresher course there is a possibility of inter-observer variation, which was not tested. Still, this represents clinical practice and makes our results better applicable. Furthermore, there were missing echocardiographic values ( $n=50)$, in the majority $(n=40)$ caused by poor image quality due to obesity, cachexia, or COPD. In a minority of cases $(n=10)$ in psychogeriatric residents, there was resistance to the echocardiography. There was no cross-validation used for testing the logistic regression model, which may have resulted in a slightly over optimistic model, but if cross-validation had been used, the number of residents would have been smaller, leading to inaccurate results.

Finally, the participation rate was limited (27\%). A consideration here is that legal representatives often do not want to decide for participation on behalf of demented residents, which explains 
the lower participation rate of psychogeriatric patients. Our findings are in line with a study conducted by Barnes [27] on HF in the elderly, where only $30 \%$ of patients agreed to participate. Still, residents included did not differ in a clinical meaningful way from those that did not agree to participate.

\section{Conclusion}

Our study showed that the physicians attending the nursing home were fairly capable of diagnosing HF in nursing home residents without the information of echocardiography. Still, echocardiography may be indicated in a group of residents if treatment decision are dependent on knowing LVEF or if valvular disease is considered as main underlying cause. A model to predict HF when the NHP has doubt about the diagnosis of HF contributes to a more accurate diagnosis of HF in nursing home residents.

\section{Ethical statement}

The study protocol complied with the declaration of Helsinki and has been granted approval from the Medical Ethics Committee of Maastricht University/Academic Hospital Maastricht (NL33281.068.10/MEC10-3-074). The study has been registered in the Netherlands National Trial Register (NTR2663).

\section{Funding}

This study was funded by an unrestricted grant from the Dutch Organisation for Health Research and Development (ZonMw), grant number 60-61900-98-303.

\section{Disclosure of interest}

The authors declare that they have no competing interest.

\section{References}

[1] Bleumink GS, Knetsch AM, Sturkenboom MC, Straus SM, Hofman A, Deckers JW, et al. Quantifying the heart failure epidemic: prevalence, incidence rate, lifetime risk and prognosis of heart failure The Rotterdam Study. Eur Heart J 2004;25(September (18)):1614-9.

[2] Hancock HC, Close H, Mason JM, Murphy JJ, Fuat A, Singh R, et al. High prevalence of undetected heart failure in long-term care residents: findings from the Heart Failure in Care Homes (HFinCH) study. Eur J Heart Fail 2013;15(February (2)):158-65.

[3] Schols JM. Nursing home medicine in The Netherlands. Eur J Gen Pract 2005;11(September-December (3-4)):141-3.

[4] Ponikowski P, Voors AA, Anker SD, Bueno H, Cleland JG, Coats AJ, et al. 2016 ESC Guidelines for the diagnosis and treatment of acute and chronic heart failure: The Task Force for the diagnosis and treatment of acute and chronic hear failure of the European Society of Cardiology (ESC). Developed with the special contribution of the Heart Failure Association (HFA) of the ESC. Eur J Heart Fail 2016;18(August (8)):891-975.

[5] Lien CT, Gillespie ND, Struthers AD, McMurdo ME. Heart failure in frail elderly patients: diagnostic difficulties, co-morbidities, polypharmacy and treatment dilemmas. Eur J Heart Fail 2002;4(January (1)):91-8.

[6] Heckman GA, Patterson CJ, Demers C, St.Onge J, Turpie ID, McKelvie RS. Heart failure and cognitive impairment: challenges and opportunities. Clin Interv Aging 2007;2(2):209-18.

[7] de Freitas EV, Batlouni M, Gamarsky R. Heart failure in the elderly. J Geriatr Cardiol 2012;9(June (2)):101-7.

[8] Butler J, Fonarow GC, Zile MR, Lam CS, Roessig L, Schelbert EB, et al. Developing therapies for heart failure with preserved ejection fraction: current state and future directions. JACC Heart Fail 2014;2(April (2)):97-112.
[9] Clark MA, Arnold SV, Duhay FG, Thompson AK, Keyes MJ, Svensson LG, et al. Five-year clinical and economic outcomes among patients with medically managed severe aortic stenosis: results from a Medicare claims analysis. Circ Cardiovasc Qual Outcomes 2012;5(September (5)):697-704.

[10] Gaulden L. Diagnosis and management of heart failure in the long-term care setting. Director 2003;11(Fall (4)):177-81.

[11] Hoek JF, Ribbe MW, Hertogh CMPM, van der Vleuten CPM. The Specialist Training Program for Nursing Home Physicians: a New Professional Challenge. J Am Med Dir Assoc 2001;2(6):326-30.

[12] Hobbs FD. Unmet need for diagnosis of heart failure: the view from primary care. Heart 2002;88(October (Suppl. 2)). ii9-11.

[13] Wheeldon NM, MacDonald TM, Flucker CJ, Mckendrick AD, McDevitt DG Struthers AD. Echocardiography in chronic heart failure in the community. Q J Med 1993;86(January (1)):17-23.

[14] Barents M, van der Horst IC, Voors AA, Hillege JL, Muskiet FA, de Jongste MJ. Prevalence and misdiagnosis of chronic heart failure in nursing home residents: the role of B-type natriuretic peptides. Neth Heart J 2008;16(April $(4)): 123-8$

[15] Daamen MA, Hamers JP, Gorgels AP, Brunner-la Rocca HP, Tan FE, van DieijenVisser MP, et al. The prevalence and management of heart failure in Dutch nursing homes; design of a multi-centre cross-sectional study. BMC Geriatr 2012;12:29.

[16] Lang RM, Bierig M, Devereux RB, Flachskampf FA, Foster E, Pellikka PA, et al. Recommendations for chamber quantification: a report from the American Society of Echocardiography's Guidelines and Standards Committee and the Chamber Quantification Writing Group, developed in conjunction with the European Association of Echocardiography, a branch of the European Society of Cardiology. J Am Soc Echocardiogr 2005;18(December (12)):1440-63.

[17] McMurray JJ, Adamopoulos S, Anker SD, Auricchio A, Bohm M, Dickstein K, et al. ESC Guidelines for the diagnosis and treatment of acute and chronic heart failure 2012: The Task Force for the Diagnosis and Treatment of Acute and Chronic Heart Failure 2012 of the European Society of Cardiology. Developed in collaboration with the Heart Failure Association (HFA) of the ESC. Eur Heart J 2012;33(July (14)):1787-847.

[18] Hajian-Tilaki K. Receiver operating characteristic (ROC) curve analysis for medical diagnostic test evaluation. Casp J Intern Med 2013;4(Spring).

[19] Sztramko R, Chau V, Wong R. Adverse drug events and associated factors in heart failure therapy among the very elderly. Can Geriatr J 2011;14(December (4)):79-92.

[20] Mosterd A, Deckers JW, Hoes AW, Nederpel A, Smeets A, Linker DT, et al. Classification of heart failure in population based research: an assessment of six heart failure scores. Eur J Epidemiol 1997;13(July (5)):491-502.

[21] Oudejans I, Mosterd A, Bloemen JA, Valk MJ, van Velzen E, Wielders JP, et al. Clinical evaluation of geriatric outpatients with suspected heart failure: value of symptoms, signs, and additional tests. Eur J Heart Fail 2011;13(May (5)):518-27

[22] Hogg K, Swedberg K, McMurray J. Heart failure with preserved left ventricular systolic function; epidemiology, clinical characteristics, and prognosis. J Am Coll Cardiol 2004;43(February (3)):317-27.

[23] Mancia G, Fagard R, Narkiewicz K, Redon J, Zanchetti A, Böhm M, et al. 2013 ESH/ESC Guidelines for the management of arterial hypertension: the Task Force for the management of arterial hypertension of the European Society of Hypertension (ESH) and of the European Society of Cardiology (ESC). J Hypertens 2013;31(July (7)):1281-357.

[24] Fox K, Garcia MAA, Ardissino D, Buszman P, Camici PG, Crea F, et al. Guidelines on the management of stable angina pectoris: executive summary: The Task Force on the Management of Stable Angina Pectoris of the European Society of Cardiology. Eur Heart J 2006;27(June (11)):1341-81.

[25] Fihn SD, Gardin JM, Abrams J, Berra K, Blankenship JC, Dallas AP, et al. 2012 ACCF/AHA/ACP/AATS/PCNA/SCAI/STS Guideline for the Diagnosis and Management of Patients With Stable Ischemic Heart DiseaseA Report of the American College of Cardiology Foundation/American Heart Association Task Force on Practice Guidelines, and the American College of Physicians, American Association for Thoracic Surgery, Preventive Cardiovascular Nurses Association, Society for Cardiovascular Angiography and Interventions, and Society of Thoracic Surgeons, Journal of the American College of Cardiology. Circulation 2012;60(24):e44-164.

[26] Nishimura RA, Otto CM, Bonow RO, Carabello BA, Erwin III JP, Guyton RA, et al. 2014 AHA/ACC Guideline for the Management of Patients With Valvular Heart Disease: A Report of the American College of Cardiology/American Heart Association Task Force on Practice Guidelines. Circulation 2014;129(June (23)):e521-643.

[27] Barnes S, Gott M, Payne S, Parker C, Seamark D, Gariballa S, Small N. Recruiting older people into a large, community-based study of heart failure. Chronic Illn 2005;1(4):321-9. 